\title{
Immunoelectron microscopic demonstration of fibronectin in rheumatoid pannus and at the cartilage-pannus junction
}

\author{
SHUNICHISHIOZA WA*AND MORRIS ZIFF \\ From the Rheumatic Diseases Unit, Department of Internal Medicine, the University of Texas Health Science \\ Center at Dallas, Texas, USA
}

SUMMARY The presence of fibronectin (Fn) in rheumatoid pannus was investigated by an immunoelectron microscopic method using horseradish peroxidase-conjugated antibody to stain Fn. Large amounts of Fn were demonstrated in the interstitial collagenous tissue of invasive rheumatoid pannus. Fn was also observed on the surface of both fibroblast-like and macrophagelike pannus cells, suggesting that it was secreted by these cells and that the secreted Fn might facilitate the spreading of the pannus cells over the cartilage matrix. However, decreased amounts of Fn were observed in areas of contact between pannus cells and the cartilage matrix. The reduction in the amount of Fn demonstrable at the cartilage-pannus junction may be a consequence either of proteolysis of Fn by enzymes secreted at the junction, inhibition of Fn synthesis in cells in contact with cartilage matrix, or transfer of Fn from the pannus cell surface to collagen of the cartilage matrix.

Fibronectin (Fn) is a cell surface glycoprotein of fibroblasts $^{1}$ and other cell types ${ }^{2-4}$ which is believed to have an important role in the adherence and spreading of these cells on substrates. ${ }^{5-7}$ The plasma contains an Fn of slightly different physicochemical characteristics. ${ }^{8}$ Antisera against the plasma and cell varieties readily cross-react, indicating the similarities between these molecules. ${ }^{9}$ Both cell and plasma Fn mediate the attachment of normal ${ }^{6}$ and transformed ${ }^{5}$ cells to collagenous substrates.

In rheumatoid arthritis proliferating synovial membrane or pannus covers and invades the cartilage, frequently leading to severe injury to this tissue. ${ }^{10}$ Increased levels of $F n$ have been reported in rheumatoid synovial fluids. ${ }^{112}$ It has also been demonstrated in pannus tissue by an immunofluorescent staining technique. ${ }^{13}$ In view of its role in cell adherence and spreading, it is possible that Fn produced in situ participates in the adherence of the synovial tissue to the cartilage and its invasion of the

Accepted for publication 24 March 1982.

Correspondence to Morris Ziff, MD, Department of Internal Medicine, University of Texas Health Science Center, 5323 Harry Hines Boulevard, Dallas, Texas 75235, USA.

*Present address: North Hyogo Medical and Orthopedic Center, Department of Medicine, 669-52, Japan. matrix. For this reason the presence of $F n$ in the pannus and at the cartilage-pannus junction (C-P junction) was investigated by immunoelectron microscopy using horseradish peroxidase-conjugated antibodies to stain these tissues. Fn staining material was observed in large amounts in the interstitial tissues of active rheumatoid pannus and on the surface of pannus cells. However, at the points of contact between pannus and cartilage decreased amounts of Fn were stained.

\section{Materials and methods}

Samples of cartilage covered with pannus were obtained during joint surgery from 5 patients with classical rheumatoid arthritis. ${ }^{14}$ Tissue specimens were cut in small pieces and fixed in $2 \%$ paraformaldehyde, $0.075 \mathrm{M}$ lysine, and $0.01 \mathrm{M}$ sodium periodate solution for 4 hours at $4^{\circ} \mathrm{C}$ as described by McLean and Nakane. ${ }^{15}$ They were then washed with phosphate-buffered saline (PBS), pH 7.2, for 24 hours. Tissue sections of approximately $50 \mu \mathrm{m}$ thickness were treated with the IgG fraction of rabbit antihuman fibronectin antibody (Cappel Laboratories, Downingtown, Penn in a dilution of $1: 10$ ) for 4 hours at room temperature with agitation 
and then at $4^{\circ} \mathrm{C}$ overnight. Communication with $\mathrm{Dr}$ W. J. Stegeman of Cappel Laboratories disclosed that this antibody preparation has been extensively absorbed with whole plasma (lacking cold insoluble globulin) coupled to Sepharose-4B. The antibody preparation at a protein concentration of $100 \mathrm{mg} / \mathrm{ml}$ did not react with human fibrinogen or any other plasma protein by double immunodiffusion even after repeatedly refilling of antigen and antibody wells to increase sensitivity. Control tissue sections were incubated in identical fashion with normal rabbit IgG. After washing with PBS for 24 hours the sections were reacted with horseradish peroxidase (HRP)-conjugated IgG fraction of sheep antirabbit IgG (Cappel) for 4 hours at room temperature with agitation and then at $4^{\circ} \mathrm{C}$ overnight. They were then washed with PBS and reacted with diaminobenzidine- $\mathrm{H}_{2}-\mathrm{O}_{2}$ solution, ph $7 \cdot 6$, for 30 minutes at room temperature as described by Graham and Karnovsky. ${ }^{16}$ Sections were then fixed with $1 \% \mathrm{OsO}_{4}$ for 1 hour at $4^{\circ} \mathrm{C}$, dehydrated in graded alcohol, and embedded in Epon 812. Sections $100 \mathrm{~nm}$ thick were cut perpendicularly to the articular surface with an LKB microtome and examined for

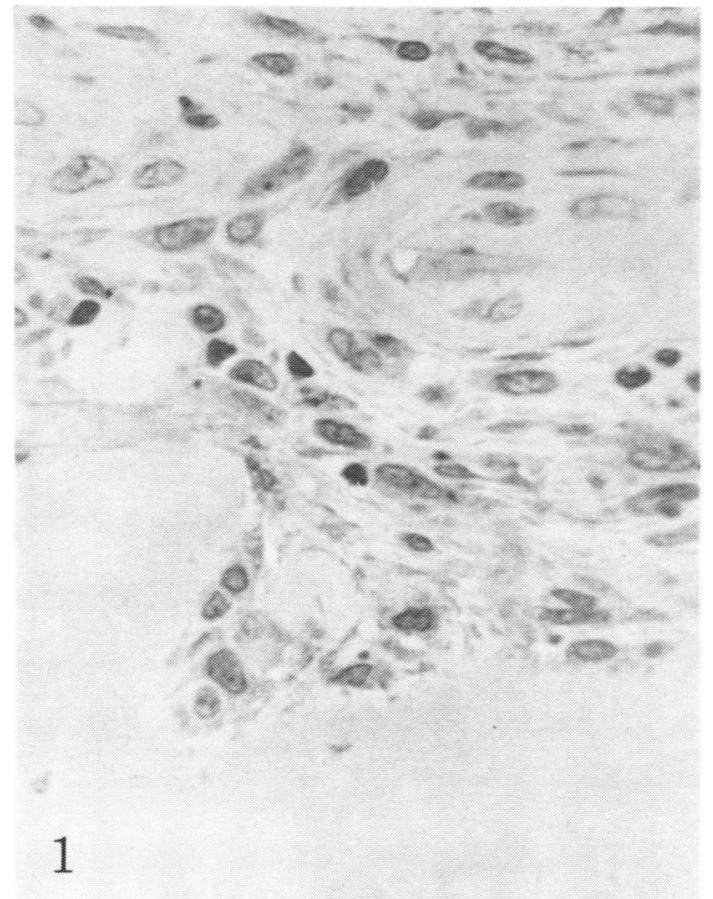

Fig. 1 Light microscopic view of active rheumatoid pannus. Perivascular cellular infiltrates and invasion of cartilage by the pannus are observed. Stained with toluidine blue. $(\times 335)$. peroxidase staining in a Phillips 300 electron microscope without counterstaining in order to observe small degrees of electron-dense staining. In order to evaluate the degree of penetration of the HRP antibodies, control studies, in which the depth of penetration of (HRP)-conjugated IgG antibodies at the C-P junction was measured, were carried out. ${ }^{17}$ On the basis of the results obtained, which showed penetration to a depth of $30 \mu \mathrm{m}$ from the cut surface, the ultrathin tissue sections examined were selected from areas which were within $15 \mu \mathrm{m}$ of the cut surface of the specimen.

In each of the 5 patients at least 20 different areas of the tissue were examined. In all experiments a positive control using HRP-anti-Fn and a negative control using HRP-normal rabbit IgG for staining were included. To confirm the specificity of the HRP staining for Fn, tissues from 2 rheumatoid patients were stained with anti-Fn antibody preabsorbed with human Fn (Sigma Chemical Company, St Louis, Mo). This absorption was carried out by coating Fn on to a plastic dish and layering on the HRP-anti-Fn antibody.

\section{Results}

HRP STAINING FOR FIBRONECTIN IN RHEUMATOID PANNUS

Pannus containing perivascular infiltrates of mononuclear cells and classified as active by previous criteria ${ }^{10}$ was examined in this study (Fig. 1). Almost all areas of such tissue obtained from 5 rheumatoid patients showed strong HRP staining for Fn in the interstitial collagenous tissues of the invading pannus (Figs. 2A, 4). The major portion of interstitial staining for Fn appeared to be present on collagen fibrils leading to visualisation of the fine structure of the collagen fibrils (Figs. 2A, 3A). Staining for Fn was also observed on fine reticular structures in the interstitum (Figs. 2A, 3A) which may represent newly synthesised Fn unassociated with collagen fibrils ${ }^{18}$ but may also represent Fn bound to matrix material. Some of the interstitial staining appeared to be present on fibrin. Control sections stained with normal rabbit IgG and HRP antirabbit IgG did not show staining (Figs. 2B, 2C, 3B). In tissue from 2 patients antifibrinogen antibody, which was applied before HRP-anti-Fn antibody, did not reduce the staining for Fn. On the other hand when the same tissues were stained with anti-Fn antibody preabsorbed with human Fn there was complete absence of Fn staining.

The surfaces of pannus cells also stained strongly for Fn. Both fibroblast-like and macrophage-like cells of the pannus were stained (Figs. 2A, 4). On the surface of these cells, especially on fibroblast-like cells, clustered areas of dense staining for Fn were 


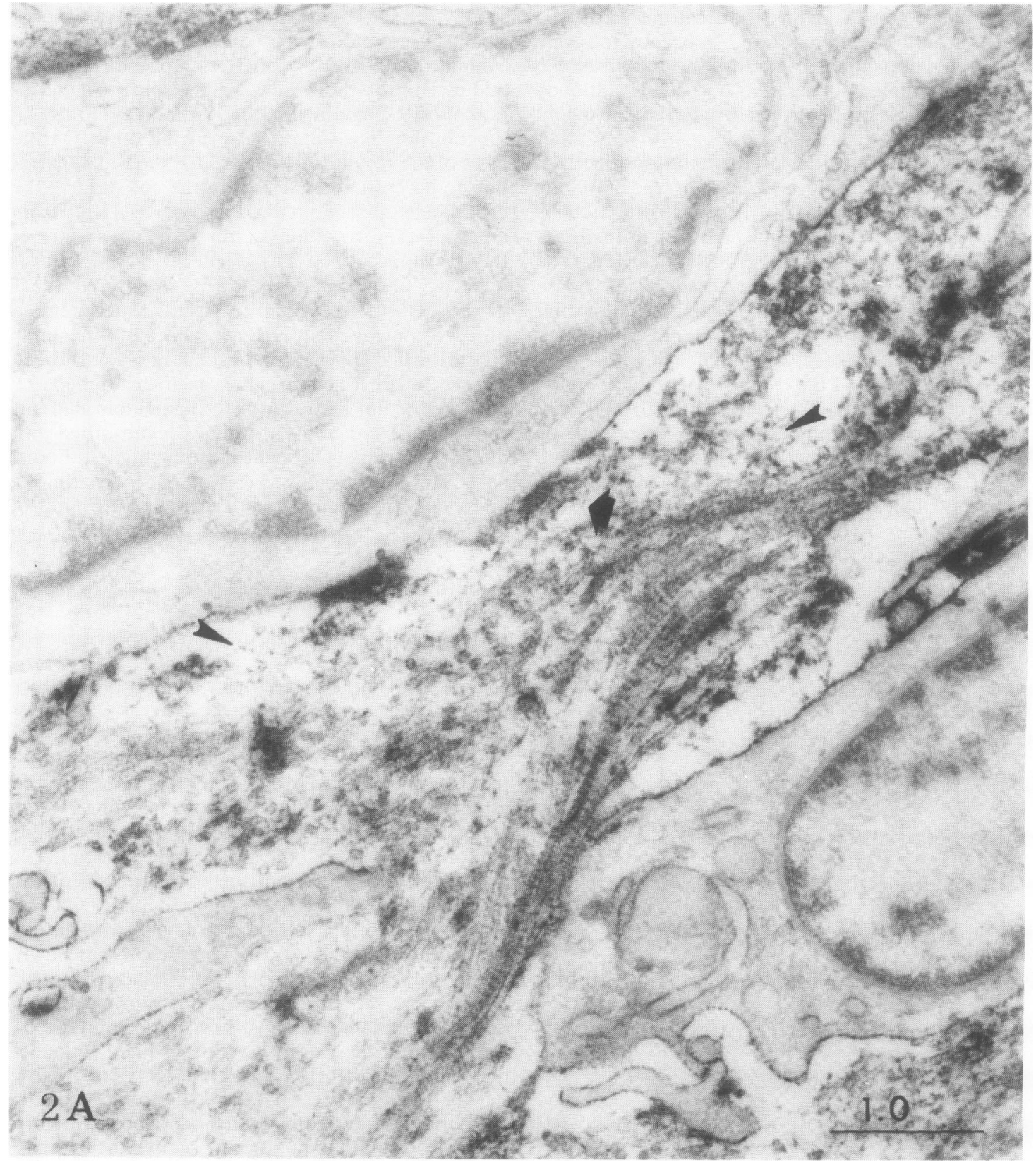

Fig 2A Rheumatoid pannus stained first with the IgG fraction of rabbit antihuman fibronectin antibody and then with the HRP-conjugated IgG fraction of sheep antirabbit IgG antibody without counterstaining. Both the cell surface of 2 fibroblast-like cells and interstitial tissue are stained. The collagen fibrils stain for fibronectin (Fn), showing their periodic structure. The arrows indicate clustered dense staining for Fn on the cell surface. A fine reticular network of material staining positively for Fn is also observed (arrowhead). ( $\times 21500)$. 


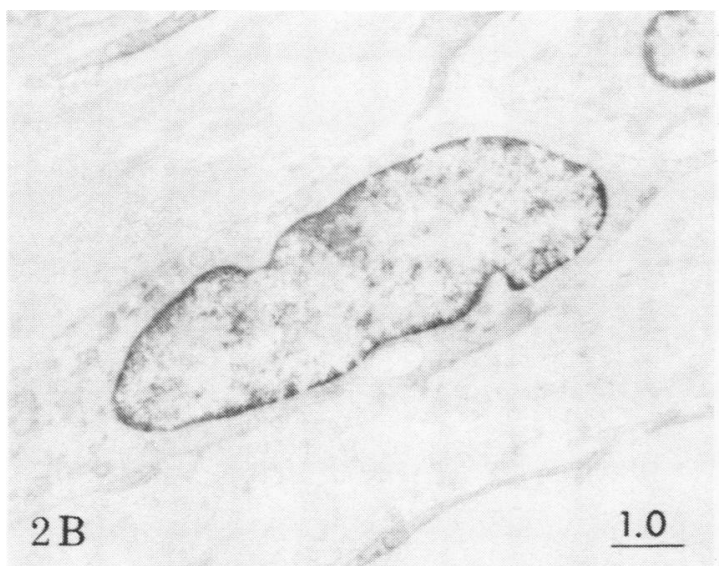

Fig. 2B Control section stained with normal rabbit $\lg G$ instead of rabbit antihuman Fn. Note the absence of staining on the cell surface and in the interstitium. ( $\times 6925)$.

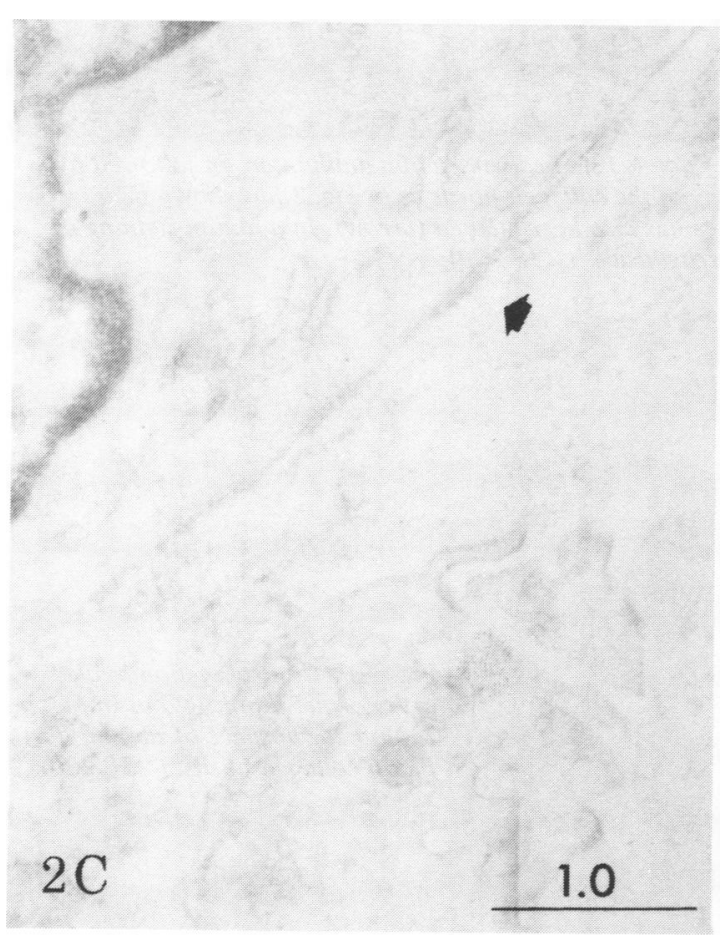

Fig. 2C Magnified view of a control section similar to $B$. Clustered dense material on cell surface is not stained (arrow). $(\times 19630)$. observed (Figs. 2A, 3A). This staining was frequently associated with pit-like indentations in the cell membrane (Fig. 5). Fn staining of the interstitial tissue was usually stronger in the vicinity of the cell surface (Fig. 6).

\section{FIBRONECTIN AT THE CARTILAGE-PANNUS JUNCTION}

Strong staining for Fn was observed throughout the pannus tissue. At the C-P junction, where pannus cells were in contact with cartilage matrix, less Fn appeared to be present. Moreover decreased staining for Fn was observed on the lower borders of the cell surfaces which were in contact with the cartilage matrix (Figs. 7-9). In contrast, the upper border of the cells showed fairly strong staining for Fn. Fig. 8 shows variable staining for Fn on the plasma membrane of cytoplasmic extensions of the invading cell. It appeared from these observations that decreased amounts of Fn were present on surfaces of cells which were in close contact with cartilage matrix.

\section{Discussion}

Immunoperoxidase staining for Fn showed the presence of fairly large amounts of Fn in the interstitial connective tissues of invasive rheumatoid pannus when examined in the electron microscope. Most of the staining appeared to be localised on collagen fibrils. These findings are consistent with previous studies of the binding of $\mathrm{Fn}$ to collagen. ${ }^{5619} \mathrm{~A}$ collagen-binding site has in fact been demonstrated on the Fn molecule. ${ }^{20-22}$ Furthermore immunofluorescence studies have shown extensive codistribution of Fn and collagen in cultures of normal fibroblasts. ${ }^{23}$

The present study also showed the presence of Fn on the cell surface of pannus cells. Both fibroblast-like and macrophage-like cells present in the pannus tissue stained positively for Fn. Areas of clustered dense staining for Fn were often observed on the surface of these cells. Fn staining of the interstitial tissue was also more intense in the vicinity of the cell surface. These findings, in conjunction with the observation of increased levels of this protein in rheumatoid synovial fluids, ${ }^{11}{ }^{12}$ suggest that $\mathrm{Fn}$ is secreted by these cells and that the secreted Fn may mediate the attachment of the pannus cells to the collagenous substratum (and its subsequent spreading over the cartilage) as previously observed by Weissmann et al. in a study of neutrophil attachment to a gelatin-coated surface. ${ }^{24}$ Grinnell and Feld ${ }^{25}$ have shown that cultured fibroblasts secrete Fn on to the surface of substrates, and this secreted Fn interacts with fibroblasts to promote further attachment. Fn has in fact been shown to enhance the attachment 


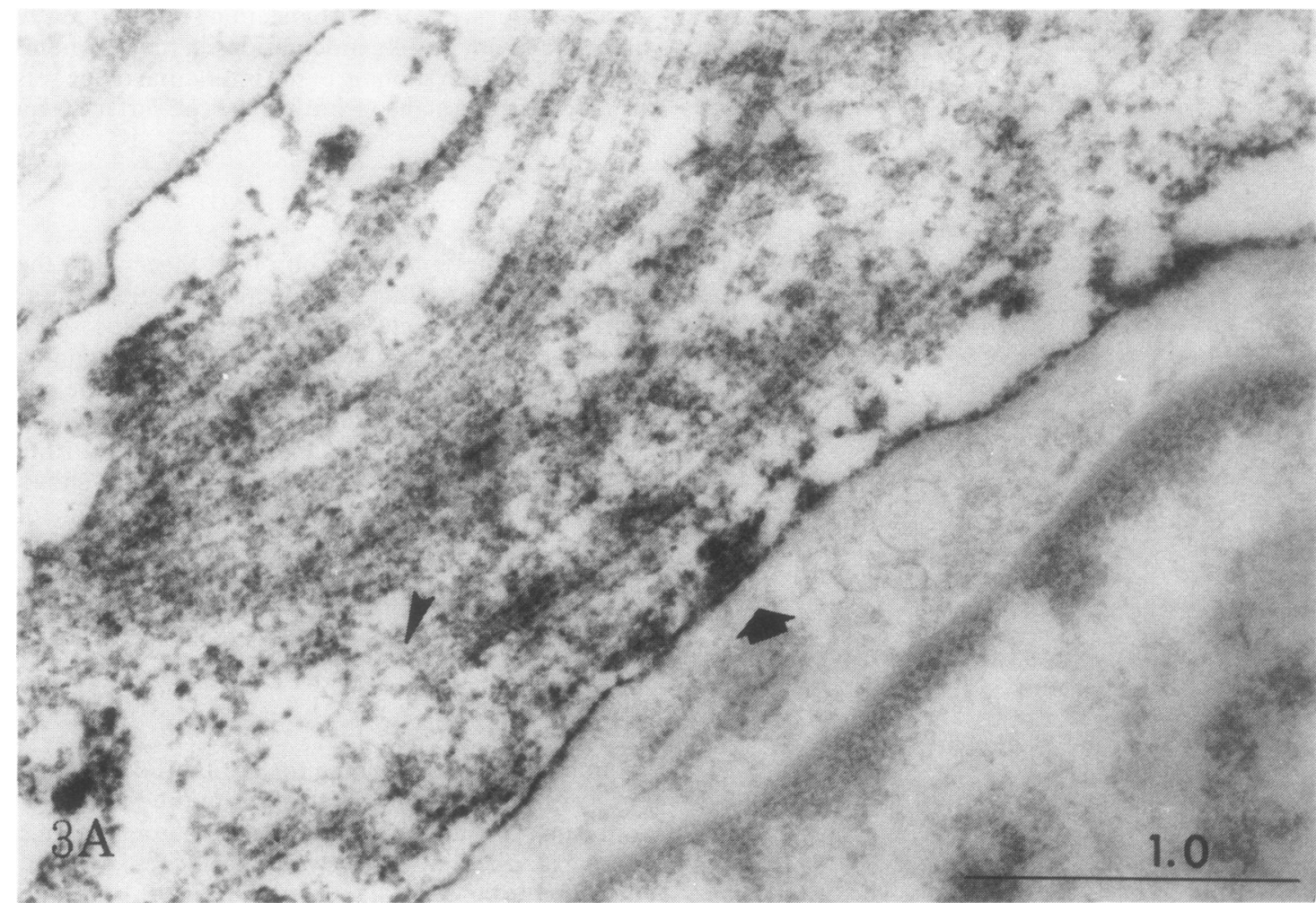

Fig. 3A Magnified view of the interstitial collagenous tissue of pannus stained with rabbit antihuman Fn followed by HRP-anti-rabbit IgG without counterstaining. The HRP staining of the collagen fibrils as in Fig. 2 has shown their periodic structure. Amorphous dense material on the cell surface has also been stained (arrow). In addition staining of fine reticular material is also observed in the interstitial area (arrowhead). $(\times 38200)$.

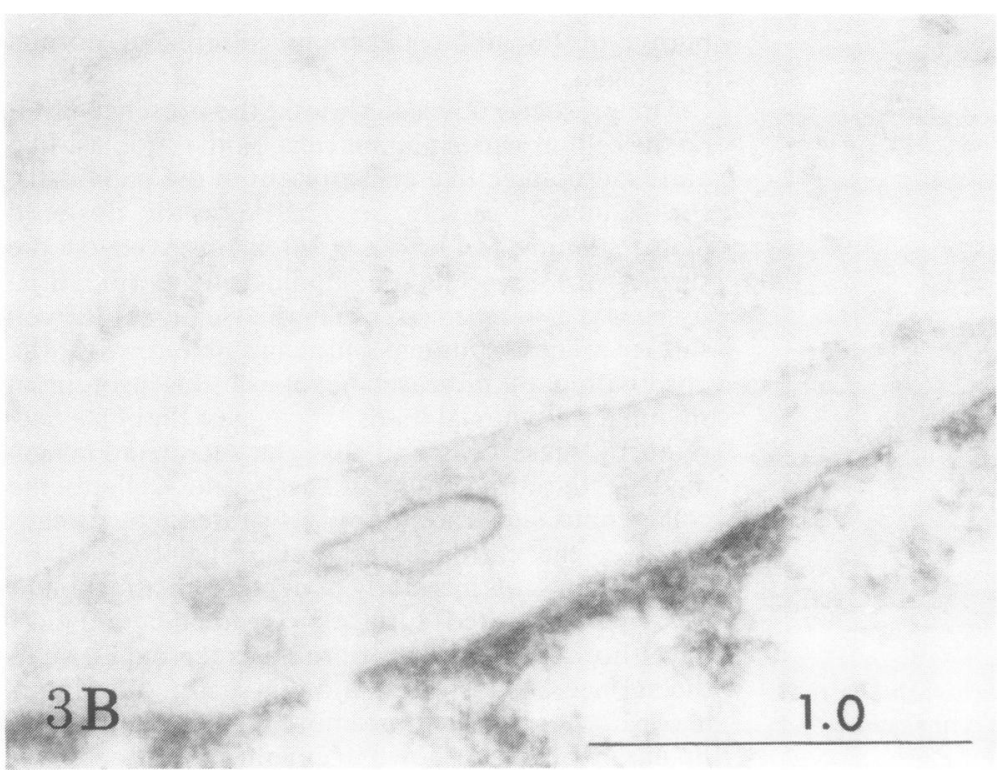

Fig. 3B Control section treated with normal rabbit $\operatorname{IgG}$ as in Fig. 2. Note the absence of staining for Fn on collagen fibrils. $(\times 38200)$. 


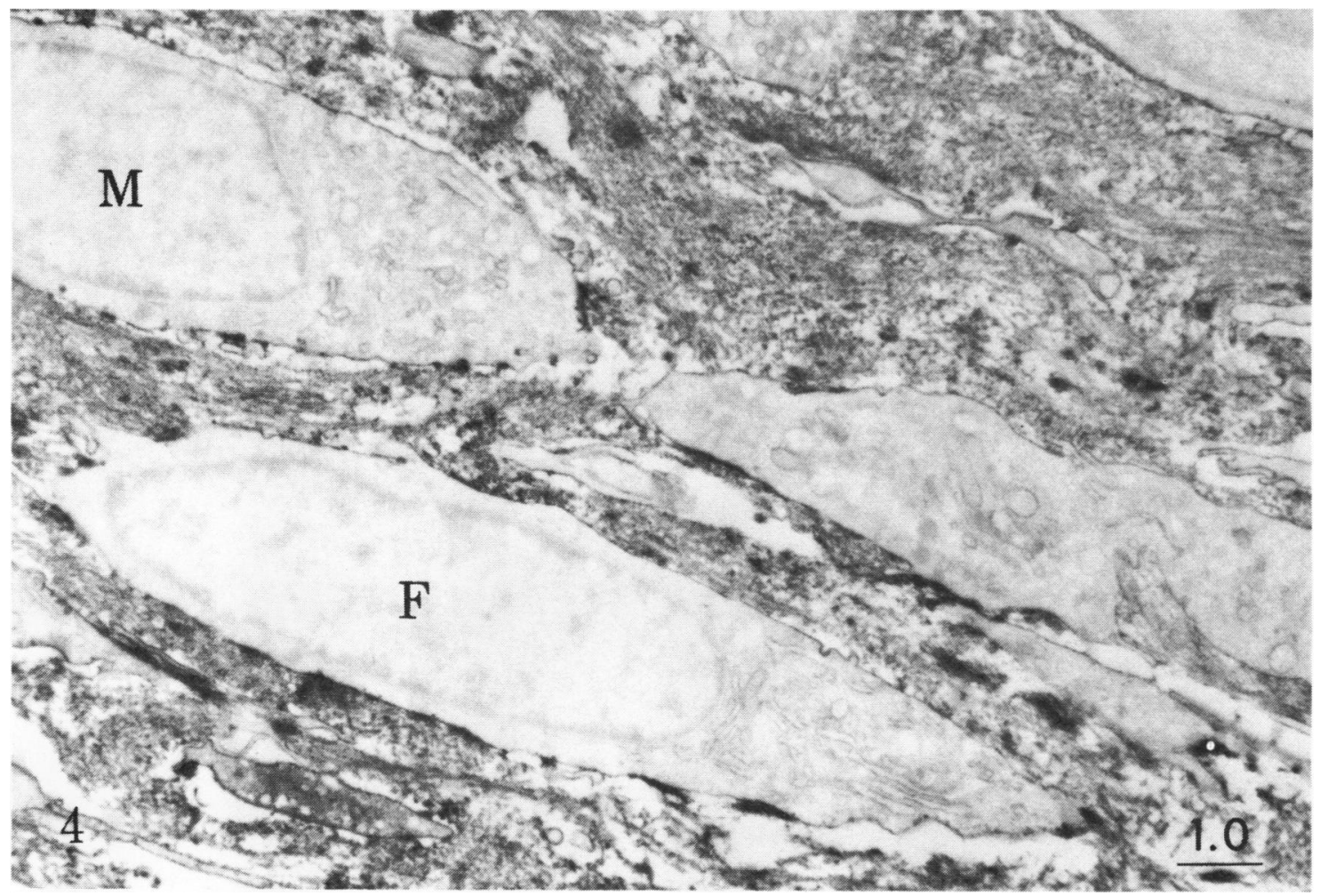

Fig. 4 Rheumatoid pannus stained first with the IgG fraction of rabbit antihuman Fn and then with the HRP-conjugated $\operatorname{IgG}$ fraction of sheep antirabbit IgG without counterstaining. Dense staining for Fn is observed in the interstitial collagenous tissue and on the surface of the pannus cells. M: macrophage-like cell. F: fibroblast-like cell. $(\times 8660)$.

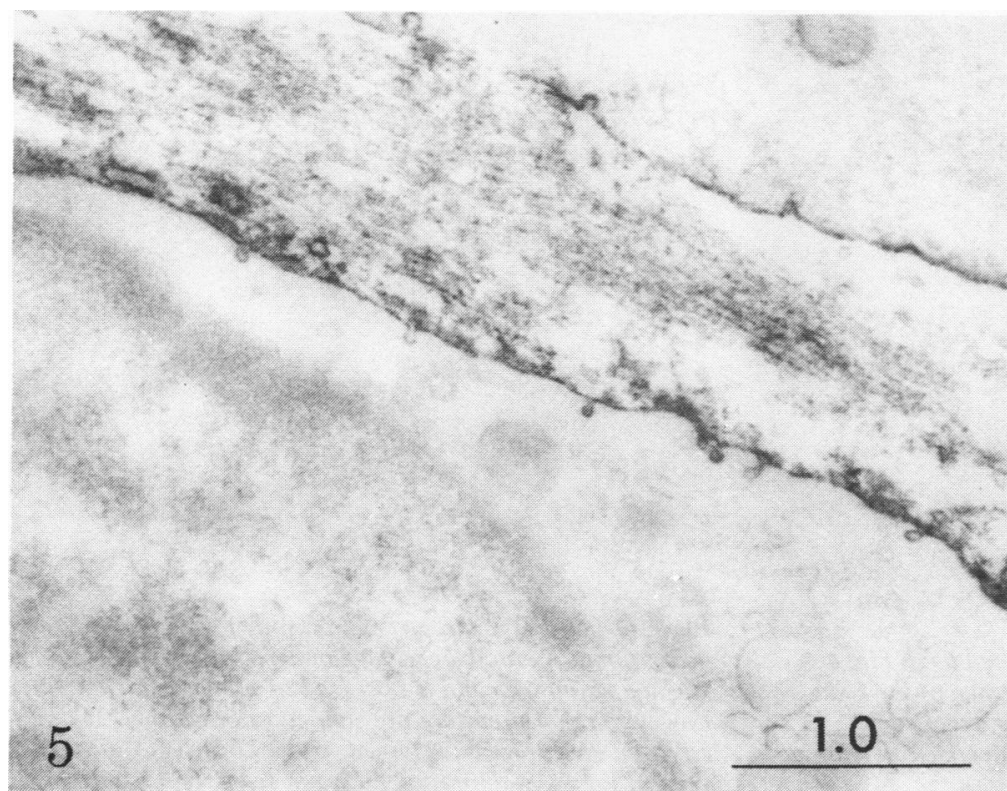

Fig. 5 Staining of pannus tissue without counterstaining as in Fig. 4. Pit-like indentations of the cell surface show HRP staining for Fn. Amorphous material showing positive staining is seen on the surface. $(\times 23100)$. 


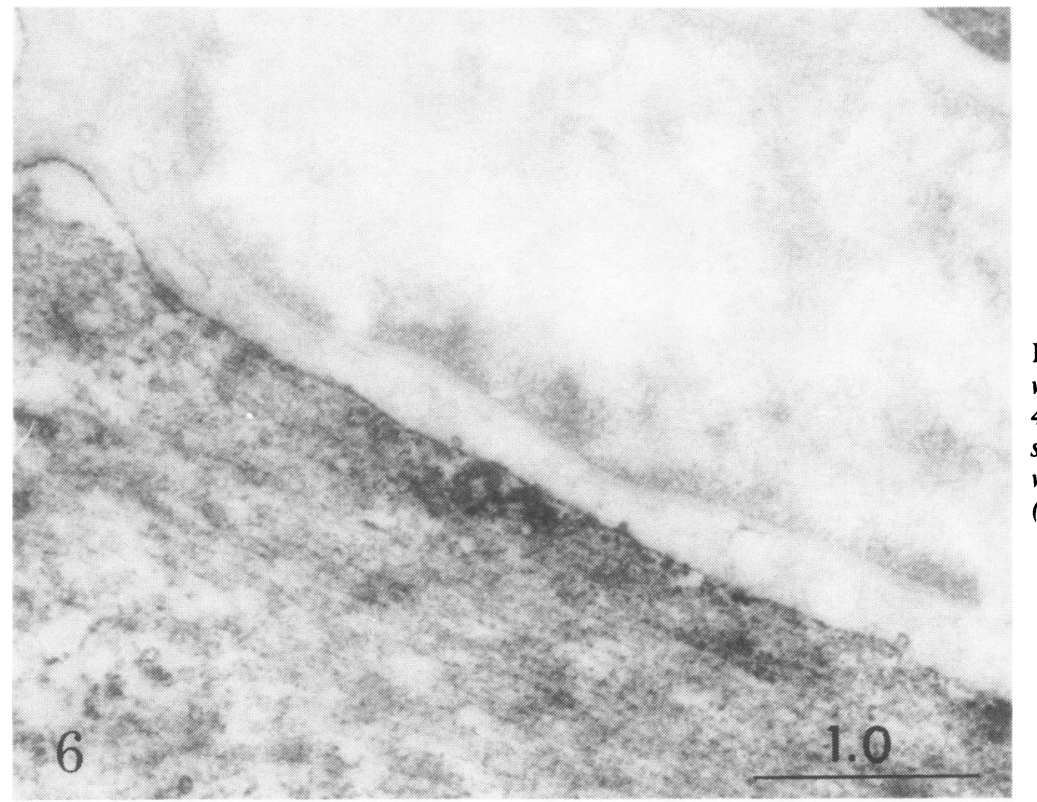

Fig. 6 Staining of pannus tissue without counterstaining as in Fig. 4. There is relatively strong staining for Fn around the cell and weaker staining at a distance. $(\times 22200)$.

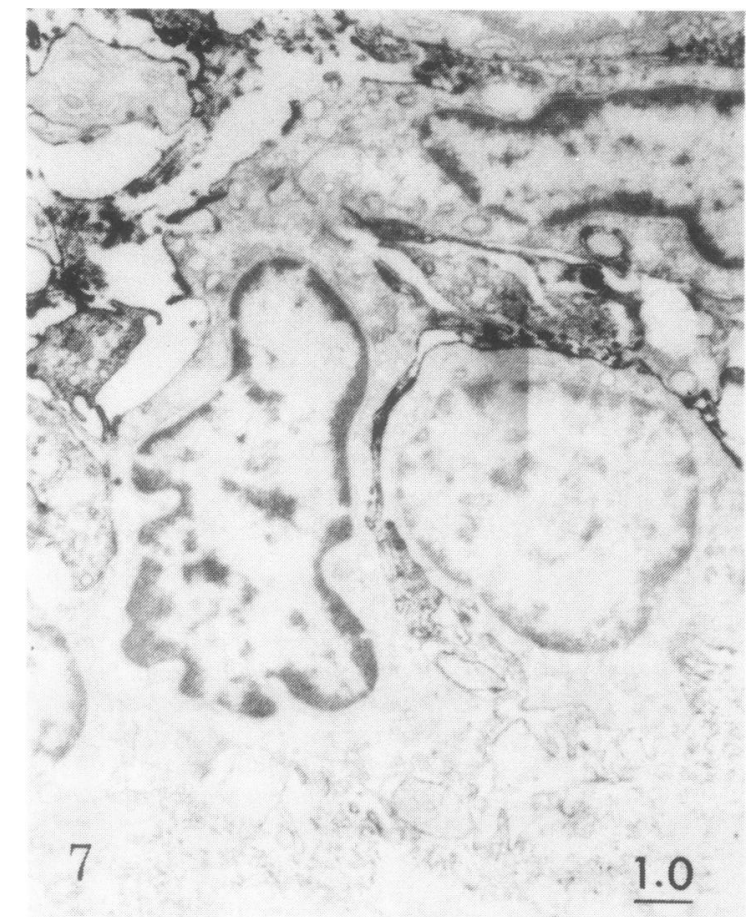

Fig. 7 Cartilage-pannus junction stained as in Fig. 4 without counterstaining. The upper surface of the cell shows HRP-positive staining, while the lower surface which contacts cartilage matrix shows decreased staining. $(\times 6830)$.

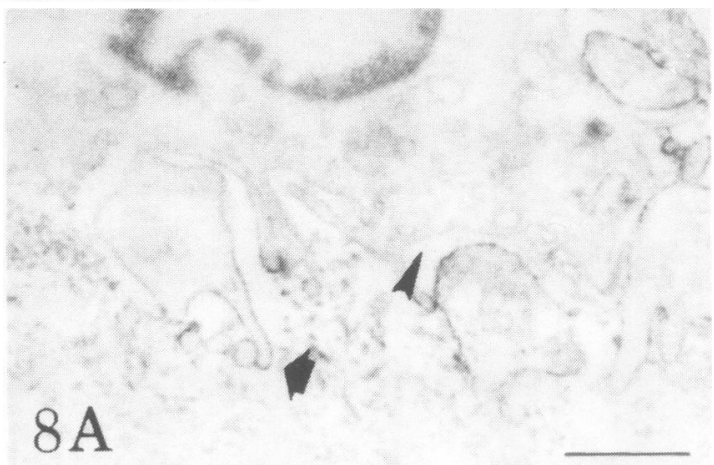

$8 \mathrm{~B}$

Fig. 8A Magnification of cytoplasmic processes which are in contact with the cartilage matrix from Fig. 7. Cell surface staining for $F n$ is observed in some areas (arrow); however, other areas are not stained (arrowhead). Matrix collagen is also weakly stained. $(\times 12200)$. B Control section for A. Staining for Fn is not seem. $(\times 11000)$. 

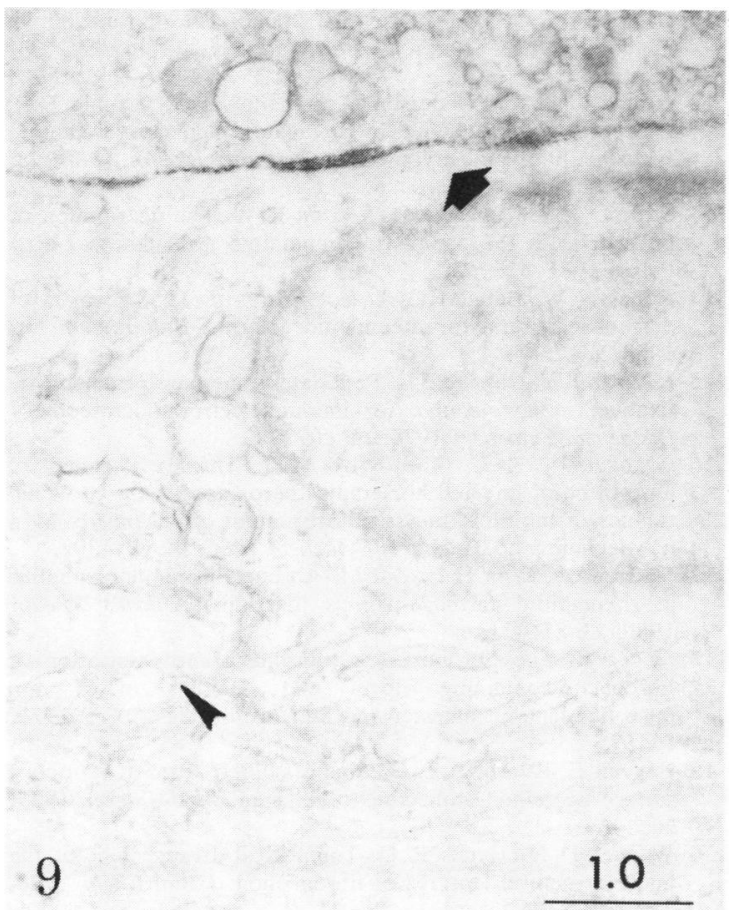

Fig. 9 Cartilage-pannus junction from another area stained as in Fig. 7 without counterstaining. In contrast to the positive HRP staining on the upper side of the cell (arrow), almost no staining is observed at the junction, possibly because the cell is undergoing degenerative change and may be releasing proteolytic enzymes. Note the disruption of the cytoplasm (arrowhead). $(\times 14700)$.

and spreading of fibroblasts ${ }^{6}$ and macrophages ${ }^{26}$ on collagenous substrata.

Kukinen et al. ${ }^{27}$ have demonstrated the sequential appearance of collagen followed by $\mathrm{Fn}$ in experimentally induced granulation tissue. The sequential appearance of collagen and $F n$ has also been observed in fibroblast cultures. ${ }^{25}$ These findings suggest that collagen-bound Fn may play a role in promoting the assembly of collagen fibrils and in this way may provide an interstitial framework proliferation of inflammatory cells. In the rheumatoid pannus Fn appears to be present mainly in the active cellular variety of pannus, since preliminary observations of inactive fibrous pannus from 2 additional rheumatoid patients showed only weak staining for this protein. The possibility existed that Fn might mediate the attachment and spreading of the pannus cells over the cartilage matrix in view of the fact that fibronectin was often stained on the cell surfaces of the invading pannus cells. Unexpected, however, was the observation that the amount of Fn stained at the C-P junction was decreased in comparison with that stained in the pannus tissue proper. This weak staining at the C-P junction noted by us in the electron microscope has also been observed at this site by Scott et al. ${ }^{13}$ using an immunofluorescent staining technique.

One possible explanation for this diminished staining at the C-P junction by the electron microscopic immunoperoxidase method would be that there was limited penetration of the antibodies used for staining at the C-P junction. To avoid this possible source of error serial ultrathin sections were obtained at depths of less than $15 \mu \mathrm{m}$ from the cut surface of the specimen, since, as previously shown, ${ }^{17}$ there is adequate penetration of HRP antibodies to a depth of at least $30 \mu \mathrm{m}$ at the level of the C-P junction. Moreover, strong staining was present in other portions of the section which lay at a similar depth from the surface.

Another possible explanation of the decreased amount of Fn staining at the C-P junction is that Fn is digested by pannus cell-derived proteases at this site. Fn has been shown to be extremely sensitive to a number of proteases, ${ }^{1928} 29$ and increased enzymatic activity does appear to be present at the C-P junction in rheumatoid joints. Woolley et al..$^{30}$ have demonstrated the presence of collagenase at the C-P junction by immunofluorescent staining. Moreover in a previous study ${ }^{17}$ the present authors have noted the absence of immunoglobulins at the C-P junction, although these were present on the free surface of the cartilage, suggesting the release of digestive enzymes at the junction.

It is also possible that the synthesis of Fn stops when pannus cells come into contact with cartilage matrix. Dessau et $a .^{31}$ observed that the in-vitro synthesis of Fn by chondrocytes ceased in the presence of intact cartilage matrix and was resumed after removal of the cartilage matrix. It is known that, although Fn is abundant in primitive mesenchyme, it disappears during differentiation of these cells into parenchymal bone, muscle, and cartilage.$^{31-34}$ These observations suggest that accumulation of certain types of extracellular matrix is accompanied by the termination of Fn synthesis. This would be consistent with the observation ${ }^{25}$ that cells harvested from postconfluent fibroblast cultures, in which a large extracellular matrix containing Fn was present, did not secrete appreciable amounts of Fn. Finally, as observed by Weissman et al. ${ }^{24}$ in the case of polymorphonuclear leucocytes in contact with gelatinSepharose beads, there may be a transfer of Fn from the cell surface to the collagen substrate leaving the surface of the cell in contact with cartilage matrix depleted of Fn.

Although Fn plays an important role in mediating cellular attachment to the substratum, it appears not 
to be absolutely required for adherence to native collagen.$^{35}$ Linsenmayer et al. ${ }^{36}$ and Kleinman et al..$^{37}$ have observed Fn-independent adherence of fibroblasts to type III native collagen. Similar results were also obtained in a macrophage system ${ }^{26}$ although Fn enhanced the attachment. It may therefore be possible that the pannus cell, once having become attached to the cartilage matrix with the participation of Fn initially, may continue to adhere to collagen without the aid of Fn.

In summary, these studies have shown the presence of large amounts of Fn in the interstitial connective tissue of invasive rhe umatoid pannus, suggesting a possible role of $\mathrm{Fn}$ in promoting pannus proliferation and adherence to cartilage. Strong staining of Fn on the surface of both fibroblast-like and macrophage-like pannus cells suggests that Fn may be produced in situ in the rheumatoid pannus. Fn was also stained at the C-P junction, but the intensity of staining was decreased in comparison with that observed in more superficial areas of the pannus. This decrease may be a result either of enzymatic digestion of Fn at the C-P junction, termination of synthesis as a result of contact of pannus cells with cartilage matrix, or transfer of Fn from pannus cell surfaces to cartilage matrix collagen following contact between the cell and the cartilage.

We thank Ms Devonda Warren for secretarial assistance and Dr Kazuko Shiozawa for discussion and help. This study was supported by USPHS Program-Project Grant AM09989.

\section{References}

1 Yamada K M, Yamada S S, Pastan I. Quantitation of a transformation-sensitive cell surface glycoprotein: decrease on several untransformed permanent cell lines.J Cell Biol 1977; 74: 649-54.

2 Vaheri A, Ruoslahti E, Westermark B, Ponten J. A common cell type specific surface antigen in cultured human glial cells and fibroblasts: loss in malignant cells. $J$ Exp Med 1976; 143: 64-72.

3 Jaffe E A, Mosher D F. Synthesis of fibronectin by cultured human endothelial cells. J Exp Med 1978; 147: 1779-91.

4 Chen L B, Maitland N, Gallimore P H, McDougall J K. Detection of the large external transformation-sensitive protein on some epithelial cells. Exp Cell Res 1977; 106: 39-46.

5 Klebe R J. Isolation of a collagen-dependent cell attach-factor. Nature 1974; 250: 248-51.

6 Pearlstein E. Plasma membrane glycoprotein which mediates adhesion of fibroblasts to collagen. Nature 1976; 262: 497-500.

7 Grinnell F. Cell spreading factor: occurrence and specificity of action. Exp Cell Res 1976; 102: 51-62.

8 Yamada K M, Olden K. Fibronectins-adhesive glycoproteins of cell surface and blood. Nature 1978; 275: 179-84.

9 Ruoslahti E, Vaheri A. Novel human serum protein from fibroblast plasma membrane. Nature 1974; 248: 789-91.

10 Kobayashi I, Ziff M. Electron microscopic studies of the cartilage-pannus junction in rheumatoid arthritis. Arthritis Rheum 1975; 18: 475-83.
11 Carsons S, Natarajan C, Drew H, Diamond H. Fibronection in human synovial fluid. Arthritis Rheum 1980; 23: 661 (abstract).

12 Iammartino A J, Anderson B, Donakowski C, Schmid F R. Detection of fibronection in rheumatoid and nonrheumatoid synovial fluids and cryoproteins. Arthritis Rheum 1980; 23: 694 (abstract).

13 Scott D L, Delamere J D, Walton K W. The distribution of fibronectin in the pannus in rheumatoid arthritis. $\mathrm{Br} J$ Exp Pathol 1981; 62: 362.

14 Ropes N W, Bennett G A, Cobb S, et al. 1958 revision of diagnostic criteria for rheumatoid arthritis. Bull Rheum Dis 1958; 9: 175-6.

15 McLean I W, Nakane P K. Periodate-lysine-paraformaldehyde fixative: a new fixative for immunoelectron microscopy. $J$ Histochem Cytochem 1974; 22: 1077-83.

16 Graham Jr, R C, Karnovsky M J. The early stages of absorption of injected horseradish peroxidase in the proximal tubules of mouse kidneys: ultrastructural cytochemistry by a new technique. J Histochem Cytochem 1966; 14: 291-302.

17 Shiozawa S, Jasin H E, Ziff M. Absence of immunoglobulins in rheumatoid cartilage-pannus junctions. Arthritis Rheum 1980; 23: 816-21.

18 Singer II. The fibronexus: a transmembrane association of fibronectin-containing fibers and bundles of $5 \mathrm{~nm}$ microfilaments in hamster and human fibroblasts. Cell 1979; 16: 675-85.

19 Engvall E, Ruoslahti E. Binding of soluble form of fibroblast surface protein, fibronectin, to collagen. Int J Cancer 1977; 20: $1-5$.

20 Wagner D D, Hynes $\mathrm{R} O$. Topological arrangement of the major structural features of fibronection. J Biol Chem 1980; 255: 4304-12.

21 Furie M B, Frey A B, Rifkin D B. Location of gelatin-binding region of human plasma fibronectin. $J$ Biol Chem 1980; 255: 4391-4.

22 Engvall E, Rouslahti E, Miller E J. Affinity of fibronectin to collagens of different genetic types and to fibrinogen.J Exp Med 1978; 147: 1584-95.

23 Vaheri A, Kurkinen M, Lehto V-P, Linder E, Timpl $\mathbf{R}$. Codistribution of pericellular matrix proteins in cultured fibroblasts and loss in transformation: fibronectin and procollagen. Proc Natl Acad Sci USA 1978; 75: 4944-8.

24 Weissmann G, Pearlstein E, Perez H D, Falkow S, Goldstein I M, Hoffstein S T. Neutrophils synthesize and deposit fibronectin on surfaces to which they attach. Trans Assoc Am Phys in press.

25 Grinnell F, Feld M K. Initial adhesion of human fibroblasts in serum-free medium: possible role of secreted fibronectin. Cell 1979; 17: 117-29.

26 Hormann H, Jelinic V. Fibronectin VII: Binding of cold-insoluble globulin and of denatured collagen by macrophages. Hoppe-Seyler's Z Physiol Chem 1980; 361: 379-87.

27 Kurkinen M, Vaheri A, Roberts P J, Stenman S. Sequential appearance of fibronection and collagen in experimental granulation tissue. Lab Invest 1980; 43: 47-51.

28 Blumberg $\mathrm{P}$ M, Robbins $\mathrm{P}$ W. Effect of proteases on activation of resting chick embryo fibroblasts and on cell surface proteins. Cell 1975; 6: 137-47.

29 Zetter B R, Chen L B, Buchanan J M. Effects of protease treatment on growth, morphology, adhesion, and cell surface proteins of secondary chick embryo fibroblasts. Cells 1976; 7: 407-12.

30 Woolley D E, Crossley M J, Evanson J M. Collagenase at sites of cartilage erosion in the rheumatoid joint. Arthritis Rheum 1977; 20: 1231-9.

31 Dessau W, Sasse J, Timpl R, Jlek F, von der Mark K Synthesis and extracellular deposition of fibronectin in 
chrondrocyte cultures. Response to the removal of extracellular cartilage matrix. J Cell Biol 1978; 79: 342-55.

32 Linder E, Vaheri A, Ruoslahti E, Wartiovaara J. Distribution of fibroblast surface antigen in the developing chick embryo. $J$ Exp Med 1975; 142: 41-9.

33 Furcht L T, Mosher D F, Wendelschafer-Crabb G. Immunocytochemical localization of fibronectin (LETS protein) on the surface of L6 myoblasts: light and electron microscopic studies. Cell 1978; 13: 263-71.

34 Podeski T R, Greenberg I, Schlessinger J, Yamada K M. Fibronectin delays the fusion of L6 myoblasts. Exp Cell Res 1979; 122: 317-26.
35 Grinnell F, Minter D. Attachment and spreading of baby hamster kidney cells to collagen substrata: effects of cold-insoluble globulin. Proc Natl Acad Sci USA 1978; 75: 4408-12.

36 Linsenmayer T F, Gibney E, Toole B P, Gross J. Cellular adhesion to collagen. Exp Cell Res 1978; 116: 470-4.

37 Kleinman H K, McGoodwin E B, Rennard S I, Martin G R. Preparation of collagen substrates for cell attachment: effect of collagen concentration and phosphate buffer. Anal Biochem 1979; 94: 308-12.

\section{Book review}

Care of the Arthritic Hand. 4th Edn. By Adrian E. Flatt. Pp. 305. £31·50. C. S. Mosby: London. 1983.

Not unlike a Rolls-Royce, Adrian Flatt is one of our top quality exports. Trained at the London Hospital, he has been appointed Professor to one of the most prestigious units in the United States of America, has become a doyen of American hand surgery and national consultant for the United States Air Force

He has revised his classic monograph on the care of the rheumatoid hand, which first appeared in 1963 and has deservedly reached a fourth edition. The editing has of necessity been radical, even extending to a change of book title, for the state of the subject has changed considerably. Although he says in his preface that he considers it no sin to split an infinitive, his English origins are fortunately reflected in the quality and style of the writing, which helps the reader considerably. To understand the nature and progress of a deformity requires an intimate knowledge of the anatomy and biomechanics of linked joint systems and the forces acting upon them. These are thoroughly and clearly explained. Under nonsurgical management some methods for protecting the hand against deforming forces are cited. One example relates to screw topped devices which are designed for 'right handed' use. If the role of the hands is reversed in unscrewing them, then forces applied push the finger radially or in a counter ulnar drift direction.

There are some omissions of useful methods and techniques-for example, the Oakley splint in correcting deformity; the Harrison-Nicolle fusion peg, so useful for fixing small joints; the Mannefelt wrist fusion technique, especially when employed with the Day compression staple; the Nalebuff-Millender technique of dealing with swan neck deformity. It is I suppose difficult to bury one's own offspring. On page 254 , referring to his own biflanged metal hinge prosthesis, the author says, 'I believe this device has rightly been generally abandoned in favour of a flexible implant,' and yet this edition contains 10 illustrations of this device against 6 of every other type of implant.

I feel the book deserves a better index and more extensive bibliography. The last sentence in the book is 'This edition is this bastard's view of the problem at this time. . . How refreshing to have an author print so frank an acknowledgement of the evanescent state of our knowledge in a rapidly advancing field.

This fourth edition will be a great help to all who deal with this disease and can be read with much benefit by nonmedical staif such as physiotherapists and occupational therapists. 